FACULDADE de FormaÇÃo de Professores

\title{
A EVOLUÇÃO DO SUPORTE MATERIAL, DO LIVRO AO E-BOOK: MUDANÇAS E IMPACTOS AO LEITOR CONTEMPORÂNEO ${ }^{1}$
}

\author{
Roberta Kerr dos Santos (UERJ) \\ roberta.kerr@oi.net.br
}

\section{INTRODUÇÃO}

Além de acompanhar as mudanças ocorridas nas últimas décadas relativas à modernização do suporte material, causando dúvidas constantes para os estudantes e profissionais de Letras, este estudo se propõe a refletir sobre a importância destas mudanças e seus possíveis impactos para os leitores contemporâneos. Nesta breve explanação será apresentado um resumo da evolução do suporte material, identificando as modificações que estes novos processos englobam. A partir de um quadro comparativo, conhecendo também as características do midium virtual, propomos ponderar sobre o acesso ao livro disponível na internet, principalmente aqueles de domínio público e, naturalmente, seus consequentes impactos. Surgem diversos benefícios advindos da revolução tecnológica, em relação ao acesso e comodidade, por exemplo, porém surgem também pontos adversos, como os erros na reprodução virtual dos textos escritos. Como professores e profissionais da área, devemos estar atentos e atualizados em relação às mudanças que ocorrem em nossa sociedade cada vez mais globalizada. Essas modificações impactam diretamente no direcionamento dos estudos de nossos alunos e também nos estudos que realizamos da nossa língua e literatura.

\section{Conceitos básicos}

No acompanhamento da evolução do suporte material, é imprescindível evidenciar alguns conceitos básicos em relação ao regis-

\footnotetext{
1 Trabalho apresentado, inicialmente, como parte da avaliação da disciplina "Ecdótica" no curso de Especialização em Língua Portuguesa na Faculdade de Formação de Professores e, posteriormente, na Jornada de Ecdótica, na mesma faculdade, no dia 5 de março de 2010.
} 
tro do texto escrito. Denomina-se "testemunho" todas as palavras grafadas em dado suporte, que permanece disponível para consulta através dos tempos - restringindo, naturalmente, às suas limitações de conservação. Este registro não é realizado de uma única forma, pois são três as categorias para realizá-los, sendo eles: testemunho manuscrito, datiloscrito e digitoscrito.

As próprias etimologias das expressões já sugerem as suas origens. A ação de escrever à mão - o manuscrito - revela o mais antigo e mais simples ato de escrita. Importante frisar que nos estudos de Crítica Textual, são amplamente ricas as pesquisas que envolvem a análise de manuscritos antigos para diversas investigações, como originalidade e autoria de determinada obra. Afinal, mantém-se o rascunho original, escrito autografamente ou não, preservando, sobre o papel, as marcas de intervenção na sua elaboração (rasuras e correções) (CAMBRAIA, 2005, p. 63). O rascunho original também é concebido no testemunho datiloscrito, na qual o registro é realizado através de um equipamento: a máquina datilográfica, que historicamente corroborou para a agilização da produção textual, assim como a sua reprodução. Ainda em relação à disponibilidade de recursos tecnológicos para fins da escrita, outro recurso, mais atual, determina a existência do registro digitoscrito, oriundo da digitação em teclado eletrônico, advindos pela Revolução Digital. Esse último, portanto, preceituando o fim do rascunho, pelo menos no que tange as marcas deixadas pelo escritor no papel (ou outro suporte físico) original da obra, afinal, não aparecem na tela do computador as modificações realizadas no processo de constituição do arquivo com o texto (Ibidem, p. 64). Esta nova concepção, inclusive, implica na conceituação de ad libitum (de acordo com a vontade), já que os programas disponíveis "oferecem ao usuário uma constelação de recursos para elaborar os textos: escreve-se, apaga-se, substitui-se, muda-se a ordem, altera-se a formatação (mancha, fonte, cor etc.) - tudo com simples toques sobre um teclado ou sobre o mouse." (Ibidem, p. 176). Consequentemente, muda-se o foco em relação à investigação das obras, já que a análise será direcionada não mais para o registro e sim para a reprodução do texto. Isto porque, independente da forma da elaboração original do registro, todos podem ser reproduzidos através de cópia manuscrita, impressão ou por meio digital, sendo este último 
uma tendência moderna através da reprodução fac-similar das obras escritas à mão ou datilografadas.

No que concerne ao conceito de livro, além de um conjunto organizado e unido de folhas, segundo Houaiss, define-se como: "obra de cunho literário, artístico, científico etc. que constitui um volume [Para fins de documentação, é uma publicação não periódica com mais de 48 páginas, além da capa.]; Livro em qualquer suporte (p.ex., papiro, disquete etc.)." (HOUAISS, 2009, s.v.). Acrescentando que este objeto é produzido a partir de três elementos principais, a citar primeiro a matéria subjetiva, ou melhor, o suporte material, objeto de estudo deste trabalho, a ser detalhado em sua evolução no próximo capítulo. Seguido da matéria aparente, que consiste propriamente na tinta produzida a partir de elementos "de origem vegetal (p. ex., noz-de-galha, azeite de oliva, vinho branco, goma-arábica), mineral (p. ex., sulfato de ferro) e animal (p. ex., mel, clara de ovo)" (CAMBRAIA, 2005, p. 68). A matéria instrumental, por último, representando o utensílio que registra a escrita no suporte, de hastes de metal ou osso, passando por estilo, cálamo, pincel, pena de ave, pena de aço, caneta-tinteiro, caneta esferográfica, lápis, dentre outros. (Ibdem, p. 69).

\section{Linha do tempo: a evolução do suporte material}

Com o passar dos tempos, é inevitável para a humanidade a manutenção de determinados hábitos e comportamentos. A evolução das tecnologias impulsiona a geração de novos recursos, sendo estes utilizados para o homem viver, se relacionar e se comunicar. Se no início dos registros escritos utilizava-se argila ou pedra para a inscrição dos primeiros textos, o desenvolvimento do ser humano em suas habilidades e criações permitiu a substituição dos suportes duros por materiais cada vez mais práticos, evidentemente, atinentes às suas épocas, oriundos dos três reinos da natureza: mineral, vegetal e animal.

Percorreremos, portanto, as características mais essenciais do papiro, pergaminho e papel até chegar ao midium mais moderno: o suporte eletrônico. Esclarecendo também, que esse percurso é imprescindível para acompanhar e avaliar os impactos pertinentes aos 
estudos e análises de textos, assim como as investigações que sobre eles são realizados no âmbito da crítica textual.

\subsection{Papiro}

Criada pelos egípcios, foi o principal suporte da escrita na Antiguidade. Naturalmente, por abranger dados históricos, há divergência sobre a época do surgimento do papiro, mas concernente ao material originário de sua produção, é notório se tratar de uma espécie vegetal (Cyperus papyrus) comum às margens do Nilo (Ibidem, p. 65). As finas lâminas extraídas do seu talo eram postas lado a lado e sobrepostas novas lâminas perpendicularmente para criar o formato de uma folha retangular. Após ser prensada, secada e polida, estava, enfim, disponível para a escrita. Sua forma de produção se realizava através de rolos, com bastões nas extremidades denominado Volume (em latim, volumen). Sobre seus registros mais antigos, estes datam de 3000 a. C., no Egito.

Outro ponto importante a respeito dos rolos de papiro envolve a existência da mais famosa de todas as bibliotecas egípcias, e com certeza a mais famosa de toda a Antiguidade, que foi a de Alexandria (MARTINS, 1996, p. 74). Sobre o número de obras guardadas no local, estimam-se o total de setecentos mil volumes, obras estas que foram perdidas através de incêndios históricos e intencionais, sendo o terceiro incêndio aquele que determinou o seu fim.

\subsection{Pergaminho}

O pergaminho consiste de pele de animal, da qual se eliminam a parte mais externa (a epiderme) e a mais e a mais interna (a hipoderme), restando, assim, a parte intermediária, que é fibrosa (a derme). Sua elaboração seguiria, grosso modo, as seguintes etapas: molho em água corrente, liberação da epiderme através de cal, eliminação dessa camada, raspagem da hipoderme, tensionamento da pele, alisamento para a tornar mais fina, polimento com pedra-pome e operações de acabamento (CAMBRAIA, 2005, p. 66). 
Os animais normalmente utilizados para a confecção do pergaminho eram o bezerro, cabra, carneiro/ovelha. Porém, há alguns bibliógrafos que afirmam terem existido livros escritos em pergaminho oriundo de pele humana.

A origem deste material, também bem antiga, data de II a. C., de um exemplar grego. A busca para elaboração de um material diferente surgiu para solucionar a falta de papiro, resultante das guerras que impediam a sua importação. Sua produção estreia o modelo de livro utilizado ainda hoje, visto que as folhas eram dobradas ao meio, formando cadernos, que eram sobrepostos, costurados e encapados com material mais firme, como a madeira, por exemplo. A este modelo se denomina códice, ou codex, em latim.

A ornamentação do objeto, por conseguinte, torna-se cada vez mais elaborada, como cita Ana Luísa Escorel: "De signo de prestígio, cheio de iluminuras e requintes artesanais como incrustação de pedras preciosas em encadernações feitas com as melhores e mais bem curtidas peles de animais disponíveis (...) (ESCOREL. A ostra e olivro, p. 1)

\subsection{Papel}

A invenção do papel é atribuída aos chineses por volta de I d. C. e introduzido na Europa através dos árabes no séc. XII, até mesmo com a existência de uma oficina de papel ao sul da Espanha em 1501. Este suporte material é constituído por elementos fibrosos vegetais, formando com água uma pasta, que é secada, prensada e alisada. Os testemunhos mais antigos foram localizados por volta de II. d. C., porém, somente com a invenção dos caracteres móveis de Gutenberg houve o aumento da reprodução e popularização dos livros.

A sua praticidade e importância pode ser percebida e ratificada com mais uma citação de Escorel:

De fato, o livro talvez seja dos mais extraordinários objetos jamais concebidos, tanto no que se refere ao aspecto físico quanto ao potencial transformador. Pequeno, portátil, livre da necessidade da reposição de peças, resistente a quedas e manuseio, barato, se comparado a produtos com os quais concorre - revistas, filmes, novelas e seriados de televisão -, trajetória segue firme desde que Gutenberg abriu o caminho para liber- 
tá-lo dos estreitos círculos da aristocracia rica, que dominavam os jogos do poder na Europa, em finais do séc. XV. (Ibidem, p. 1).

Pode-se também afirmar que, ainda hoje, eles são os principais veículos de comunicação escrita, sejam através de conteúdos científicos ou conteúdos literários. Afora este dado, o livro de papel possui importante apelo de estima e reverência atinente à sua função social e emocional. Citamos o pesquisador Wilson Martins, que declara desta forma a sua percepção sobre o objeto:

(...) o livro guarda a sua superioridade própria e venerável de veículo privilegiado, de forma pela qual a ideia se materializa e transmite. Assim, tanto quanto possível, o livro deve ser belo e valioso inclusive como objeto e deve ser agradável à vista e ao tacto, como é agradável à mente. Reduzi-lo à condição de mera mercadoria é vilipendiá-lo, é humilhá-lo na sua natureza e, o que é pior, é tornar o homem indigno dele. (MARTINS, 1996, p. 242)

Diante de tantos predicados e vínculos que se dedicam ao livro, é difícil perceber um contexto propício para uma nova mudança. Conquanto, com as diversas necessidades decorrentes pelo ritmo ágil da modernidade, este suporte - aparentemente perene na história do homem - também está sofrendo alterações.

\subsection{Eletrônico}

A Revolução Digital, referenciada pelo ano de 1980, quando os Estados Unidos atingiam a marca de mais de um milhão de computadores, proporcionou ainda mais perspectivas sobre os equipamentos e recursos utilizados na nossa comunicação. A tela do computador que, nesta década começava a se instalar nos lares de pessoas em todo o mundo, se tornou um importante recurso de arquivamento de dados e, posteriormente com o surgimento da Internet, também de transmissão de informações.

Atualmente, os testemunhos digitoscritos contam com as facilidades da escrita no teclado e, de forma ainda mais significativa, com a correção das palavras do texto no próprio arquivo digital. Conceitua-se, desta, forma, o suporte eletrônico como um componente físico capaz de reproduzir informações virtuais/digitais através do processamento de dados (informática). 
Considerando que um dos pontos importantes da informática é a possibilidade de armazenamento das informações virtuais, urge esclarecer uma questão fundamental inerente ao suporte eletrônico. Na conceituação de suporte material, definimo-lo como o recurso pelo qual se permite a leitura da obra escrita. Consequentemente, o equipamento em que este texto está embutido (ou arquivado) não o caracteriza como matéria subjetiva. Relembrando o verbete "livro" consultado no dicionário Houaiss que continha como exemplo de suporte o papiro ou disquete, é premente evidenciar que este último envolve apenas um dispositivo de arquivamento de dados, não o pressupondo ser também um suporte material, já que não é nele que se visualiza ou consulta o testemunho. Conclui-se que o disquete, o $\mathrm{CD}$, o pendrive, o memorycard etc. apenas contém a obra, ou melhor, o arquivo da obra. A própria internet, por permitir o arquivamento digital - as chamadas "bibliotecas digitais" -, além da sua divulgação online em qualquer lugar do mundo, também não são em si um suporte.

Desta forma, o suporte eletrônico é o instrumento físico capaz de reproduzir a imagem das palavras, através do monitor do computador, do display do celular ou smartphone e, mais recentemente, dos e-readers que propiciam a visualização da escrita.

O questionamento presente sobre o fim do objeto livro, a partir da sua substituição pelo recurso digital - assim como o papiro foi substituído pelo pergaminho e posteriormente este pelo papel -, muitas são as conjecturas a respeito. Como ainda é muito incipiente a presença de $e$-books no dia a dia das pessoas, no Brasil e no mundo, considera-se, portanto, precoce qualquer mudança mais brusca, inclusive por envolver um hábito enraizado que as pessoas possuem da leitura através do livro, pelo prazer ou pelos estudos.

Dados do jornal $O$ Globo, de 26 de março de 2009, nos apresentam informações relevantes sobre o assunto, como por exemplo, que de 1980 até 2007 , a população mundial cresceu $48 \%$ e o consumo do papel no mundo subiu $127 \%$ em todo o mundo. Só no nosso país, a produção de papel aumentou $167 \%$. No que se refere à produção específica para imprimir e escrever, que inclui livros, foi $200 \%$ de aumento; relativizando ao Brasil aumentou 44\%. Desta forma, até recentemente não há índices decrescentes desta realidade. Sobre o 
uso dos recursos digitais, concomitantemente amplia-se o consumo, citando, à guisa de ilustração, que o número de computadores já atingiu aproximadamente um bilhão e em dois anos esta quantidade deverá dobrar, pois até 2012, estima-se que somente no Brasil haverá pelo menos 100 milhões de computadores.

Importante acrescentar sobre o surgimento e popularização dos livros virtuais, tanto em relação a sites como o Wikisource e o Google books, que disponibilizam online aproximadamente $10 \mathrm{mi}-$ lhões de obras escaneadas, sendo estes acessíveis por qualquer usuário em qualquer lugar no mundo através da internet. E apesar de ter crescido em média $10 \%$, a participação do mercado digital nas principais editoras americanas não chega a $0,5 \%$ de seus catálogos, porém o objetivo deste mercado editorial é facilitar e incentivar ainda mais a sua ampliação.

Em relação aos equipamentos que permitem a leitura dos textos digitais, assemelhando-se à mobilidade presente nos livros tradicionais, o livro digital conta com cada vez mais modelos para comercialização. As maiores empresas de informática estão lançando as suas versões para participar neste mercado, citando a Sony e Apple, como as principais no ramo. Entretanto, foi a Amazon que alavancou este nicho com o seu produto Kindle, vendendo em 2009, 260 mil itens. Além de estabelecer parceria com os principais jornais do mundo, como por exemplo, o New York Times, nos Estados Unidos e $O$ Globo, aqui no Brasil.

Para falar sobre as previsões de um suporte material ainda em estudo, mas que já promete substituir o livro digital daqui a pelo menos 15 anos, existe a tecnologia OLED, denominado nestas áreas de estudo como e-paper. Sendo de matéria flexível, de forma ainda mais próxima ao papel, poderá propiciar a experiência de leitura semelhante ao que já estamos habituados.

\section{Do livro ao e-book: mudanças e impactos ao leitor contempo- râneo}

Diversas são as mudanças que se efetivam nas novas modalidades de matérias subjetivas, realizada através dos equipamentos digitais. E, naturalmente - assim como ocorreram com as midia anteri- 
ores -, o comportamento da sociedade se adapta aos poucos, assim como os estudos a ele pertinentes, citando principalmente os estudos da Crítica Textual, que se utiliza dos suportes existentes para investigações diversas sobre os textos.

Serão apresentados dezoito tópicos importantes, relevantes ao conteúdo abordado. Sendo eles enumerados a seguir:

\subsection{Adequação à vida moderna}

O comportamento na modernidade precisa ser prático, ágil, dinâmico e assim o suporte acompanha esse ritmo, através das suas multifuncionalidades. Assim como o aparelho celular é composto por diversos recursos, como relógio, calendário, acesso à internet etc., os livros digitais também embutem facilidades que o caracterizam como vários aparelhos em apenas um.

\subsection{Consumismo}

Assim como o mercado editorial já criava livros com design de grande apelo ao consumismo, sendo inclusive oferecidos cursos fomentando o uso crítico de estratégias que englobem mídias e suportes de leitura, os equipamentos eletrônicos também seduzem ao propor objetos que se tornam verdadeiros "sonhos de consumo", aliando consumismo a modismo. Como exemplo mais recente, citamos o lançamento do Ipad, da Apple, envolto de muitas especulações na mídia e divulgações maciças de marketing.

\subsection{Habilidade tecnológica}

Nem todos os leitores-usuários têm a experiência ou familiaridade necessária para lidar com softwares e navegação que o suporte material eletrônico exige. Caracterizando este fato como mais um fator de segregação ou seleção dos que utilizarão este recurso. 


\subsection{Questão ecológica}

Evita os pesados efeitos poluentes da indústria do papel (como o uso do cloro), porém ainda não há soluções plausíveis para o lixo tecnológico (neutralização da toxicidade do chumbo e reciclagem dos equipamentos e baterias). Para melhor entendimento da gravidade problema, é importante comentar que a chuva faz com que o chumbo entre nos lençóis do terreno e contamine os rios. A contaminação por este substância produz náusea, perda de coordenação e memória e até coma.

\subsection{Custo (\$)}

O alto custo do suporte eletrônico não permite a sua popularização, ao contrário dos livros, disponíveis em bibliotecas públicas, passíveis de trocas e empréstimos, ou mesmo na aquisição a baixo custo em sebos.

\subsection{Bateria}

Como qualquer outro equipamento eletrônico, precisa carregar a bateria.

\subsection{Volume e Mobilidade}

Em um e-book, uma memória de apenas 1,4 GB arquiva cerca de 1,5 mil livros. Desta forma é possível transitar com uma pequena biblioteca no trajeto ao trabalho ou à escola.

\subsection{Relação emissor $X$ receptor}

A internet tende a minimizar a dicotomia emissor-receptor, tornando seus usuários-leitores ao mesmo tempo consumidores e produtores de informações - através da sua opinião e interferência. 


\subsection{Percepções sensoriais}

Cada vez mais o leitor é estimulado através dos seus sentidos, em que o livro será capaz de criar um universo imagético e midiático.

\subsection{Hiperlink}

A leitura não é mais linear, já que a presença de hiperlinks sugere idas e vindas ao texto e a outros textos, propondo um novo repertório ao leitor.

\subsection{Novos gêneros textuais}

Segundo Jean-Yves Mollier: "A leitura na tela plana vai aumentar e é o desafio dos próximos dez anos, o que deverá provocar o nascimento também de novos gêneros literários, desconhecidos até gora, que vão misturar texto, imagem, som".

\subsection{Pesquisas}

A realização de pesquisas é realmente muito mais ágil através dos livros eletrônicos, bastando um comando para localizar a palavra ou trecho desejado.

\subsection{Domínio público}

Diversas obras que estão em domínio público já estão disponíveis via web para download desde 2004, através do site do MEC. É a mesma proposta do Wikisource: acessível em mais de 50 línguas diferentes.

\subsection{Publicação de obras}

Para os escritores há maior viabilidade de publicar através de arquivo digital ou em canais alternativos (site, blogue etc.), pois há diminuição de custos, além de propiciar oportunidades no mercado editorial. 


\subsection{Patrimônio cultural literário}

O arquivamento e difusão de obras digitais através da internet contribui para a preservação do patrimônio cultural e ao seu acesso. A deterioração inevitável das obras incentiva a digitalização para evitar a perda dos registros históricos.

\subsection{Formatação}

A possibilidade de perda da formatação original da obra pode contribuir para a alteração do conteúdo semântico proposto pelo autor.

\subsection{Pirataria e Copyright}

Da mesma forma que ocorre com a música, a ilegalidade na reprodução não autorizada torna-se mais comum e difundida na web. Os direitos autorais são violados, além de possibilitar a perda da fidedignidade das obras literárias.

\subsection{Erros na edição}

O grande interesse em oferecer cada vez mais livros na versão digital e em menor tempo favorece o aumento de erros nas edições disponíveis na internet.

\section{Conclusão}

O próprio monitor de um computador é apenas uma janela aberta de maneira instável sobre um 'texto' que é perfeitamente irrepresentável: é um 'hipertexto', uma enorme rede de relações virtuais que permite um número ilimitado de percursos distintos, podendo o 'leitor' navegar quase sem barreiras em um emaranhado de enunciados que ele faz aparecer ou desaparecer (...). (MAINGUENE$\mathrm{AU}, 2008)$.

Apesar de todas as especulações que envolvem os novos recursos para a leitura de textos, é sempre importante para o profissio- 
nal da área de Letras acompanhar estas mudanças a fim de permanecer atualizado sobre as possibilidades que estão por vir. Não só pelo simples ato de estar ciente sobre elas, mas também para usufruir dos recursos que surgem como facilitadores em nosso dia a dia.

Promover o interesse e gosto pela leitura e propiciar a aproximação a importantes obras literárias de forma cada vez mais acessível se torna uma realidade nos dias de hoje. E para entender esta constante mudança, abordamos a evolução do suporte envolvendo dados relevantes na percepção deste contexto, desde o papiro até a matéria subjetiva eletrônica. Entendendo, inclusive, que esta apresentação serve apenas como mais um estímulo para o contínuo aprendiz que somos.

E que seja apenas o começo.

\section{REFERÊNCIAS BIBLIOGRÁFICAS}

CAMBRAIA, César Nardelli. Introdução à crítica textual. São Paulo: Martins Fontes, 2005.

HOUAISS, Antônio; VILLAR, Mauro de Salles. Dicionário eletrônico Houaiss da língua portuguesa. 1.0. [s.1.]: Objetiva, 2009.

MAINGUENEAU, Dominique. Análise de textos de comunicação. São Paulo: Cortez, 2008.

MARTINS, Wilson. A palavra escrita: história do livro, da imprensa e da biblioteca. São Paulo: Ática, 1996.

O GLOBO. Digital. Rio de Janeiro, em 09 de maio de 2009. . Prosa \& Verso. Rio de Janeiro, em 26 de setembro de 2009.

. Segundo caderno. Rio de Janeiro, em 31 de janeiro de 2010. 